\title{
Effect of Lactobacillus paracasei HII01 on lipid profile and blood parameters in hypercholesterolemic patients: A preliminary study
}

\author{
Chaiyavat Chaiyasut ${ }^{1}$, Bhagavathi Sundaram Sivamaruthi ${ }^{2}$, Sasithorn Sirilun ${ }^{3}$, \\ Yaowalak Tirawat ${ }^{4}$, Phakkharawat Sittiprapaporn ${ }^{5}$
}

${ }^{1}$ Assistant Professor and Head, ${ }^{2}$ Postdoctoral Research Fellow, ${ }^{3}$ Assistant Professor, ${ }^{4}$ Master Student, Innovation Center for Holistic Health, Nutraceuticals and Cosmeceuticals, Faculty of Pharmacy, Chiang Mai University, Chiang Mai, Thailand, ${ }^{5}$ Assistant Professor and Head, Brain Science and Engineering Innovation Research Group, School of Anti-Aging and Regenerative Medicine, Mae Fah Luang University, Bangkok, Thailand, and Department of Anti-Aging Science, School of Anti-Aging and Regenerative Medicine, Mae Fah Luang University, Bangkok, Thailand

\section{A B S T R A C T}

Background: Probiotics are live microbes that when administered in suitable amounts, confer a health benefit on the host. Probiotics are considered as a complementary and supportive therapeutic agent for the treatment of several diseases and for the management of several disorders. Hypercholesterolemia is a major risk factor for the incidence of cardiovascular (CV) diseases. Several pharmacological and dietary approaches are proposed and used to improve the cholesterol profile. Aims and Objective: The objective of the current study was to study the effect of probiotic supplementation (Lactobacillus paracasei $\mathrm{HIO} 1$ ) on high-density lipoprotein (HDL), and low-density lipoprotein (LDL), lipopolysaccharide (LPS), and immunoglobulin A (IgA) levels in hypercholesterolemic patients. Materials and Methods: Ten hypercholesterolemic subjects were supplemented with $12.5 \times 10^{10} \mathrm{CFU}$ of HIIO1 per day for 12 weeks. Blood samples were collected at baseline and after the intervention period. The LDL-C, HDL-C, LPS, and IgA content were assessed by outsourcing and ELISA methods. Results: After 12 weeks of intervention, $\mathrm{HDL}$ (from $61.14 \pm 9.65$ to $67.29 \pm 7.99 \mathrm{mg} / \mathrm{DL}$ ), LDL (from $141.57 \pm 31.95$ to $126.29 \pm 36.23 \mathrm{mg} / \mathrm{DL}), \lg \mathrm{A}(446.31 \pm 262.00$ to $939.62 \pm 758.52 \mathrm{ng} / \mathrm{ml})$, and LPS $(113.53 \pm 40.07$ to $72.78 \pm 32.39 \mathrm{pg} / \mathrm{ml}$ ) levels were significantly changed in the probioticsupplemented group when compared to the baseline value. Conclusion: The supplementation of L. paracasei HIIO1 may help to improve the lipid profile, reduce the endotoxin level and have the impact of immune activation in hypercholesterolemic subjects. Additional studies are mandatory to disclose the favorable effect of the probiotic strain L. paracasei HIIO1.

\section{Access this article online}

Website:

http://nepjol.info/index.php/AJMS DOI: 10.3126/ajms.v11i1.26498 E-ISSN: 2091-0576

P-ISSN: 2467-9100

Key words: Probiotics; Lactobacillus paracasei; Hypercholesterolemia; High-Density Lipoprotein; Low-Density Lipoprotein

\section{INTRODUCTION}

Dyslipidemia has been documented as a noticeable riskfactor for the development of cardiovascular (CV) diseases. ${ }^{1}$ The guidelines and studies showed that statin as a main therapeutic agent to lower the low-density lipoproteincholesterol (LDL-C). ${ }^{2}$ Lowering of high- density lipoprotein cholesterol (HDL-C) is an independent forecaster of CVdiseases. ${ }^{3}$ Besides, meta-regression study suggested that the increase in HDL-C not necessarily improved the CV outcome. ${ }^{4}$ The supplementation of $39 \mathrm{mg}$ of statin reduced about 20 percent of the $\mathrm{CV}$ diseases risk, but the residual relative risk was not significantly nullified by the statin treatment. ${ }^{5-7}$ 
Lifestyle changes that include the consumption of low fat and low calories food and regular physical activities are associated with weight loss and improved the lipid profile, and reduced the risk of CV diseases. Nevertheless, the lifestyle modifications are not sufficient to lower the LDL-C, and that could not be a primary therapeutic procedure to manage the $\mathrm{CV}$ diseases. So additional pharmacological approaches are needed to address the issues of dyslipidemia and risk of CV diseases. ${ }^{8}$

Probiotics are live microorganisms that when consuming in an adequate amount, confers health benefits to the host. Lactic acid bacteria (LAB), Gram-positive microbes are the most generally used probiotic strains, which have been used for several decades in food production. In recent years, screening of potent probiotics, development of probioticsbased alternative and complementary therapeutic strategies and extend the application of probiotics in possible scientific field have been increased. Probiotics, probiotic-based foods, and health supplements were reported for their positive beneficial effects on metabolic disorders, ${ }^{9,10}$ antibiotic-associated diarrhea,${ }^{11}$ inflammatory bowel diseases, ${ }^{12}$ skin diseases, ${ }^{13}$ menopausalsymptoms, ${ }^{14}$ mental health and cognitive improvement, ${ }^{15}$ and the aging process. ${ }^{16}$ In addition, LAB strains can be used as an effective microbial factory for the production of foodgrade proteins and enzymes. ${ }^{17}$

Several in vitro, in vivo and human studies, described the cholesterol-lowering activity of probiotic interventions. ${ }^{18}$ The supplementation of Lactobacillus plantarum PH04 lowered the triglyceride level and improved the cholesterol profile in hypercholesterolemic mice model. ${ }^{19}$ Likely, another strain of L. plantarum KCTC3928 also exhibited cholesterol-lowering activity in C57BL/6 mice via modulating the bile acid excretion. ${ }^{20}$

The objective of the current study was to evaluate the cholesterol-lowering property of L. paracasei HII01 in hypercholesterolemic human subjects. The changes in HDL-C, LDL-C, lipopolysaccharide (LPS), and immunoglobulin A $(\operatorname{IgA})$ level before and after the supplementation of L. paracasei HII01 have been reported in the study.

\section{MATERIALS AND METHODS}

\section{Subjects and Intervention}

The hypercholesterolemic subjects were screened and 10 people were selected. The study procedure has been explained thoroughly to the subjects and written concern agreement was made. The demographic information of the subjects was detailed in table 1. The probiotic strain Lactobacillus paracasei HII01 was cultivated and processed as live lyophilized powder at Lactomason Co., Ltd., South Korea. The aluminum foil sachet containing L. paracasei HII01 $\left(12.5 \times 10^{10} \mathrm{CFU} / \mathrm{g}\right)$ strain was supplemented to the volunteers for 4 weeks (one sachet per day) and asked them to follow their routine lifestyle. Mae Fah Luang University ethical committee evaluated and approved the study protocol (No. REH-6215; dated 14 June 2019).

\section{Sample collection}

Blood samples were collected at baseline and after 4 weeks of intervention in a sterile blood collecting tube and stored on ice or $4^{\circ} \mathrm{C}$ until analysis.

\section{Measurement of HDL, LDL, IgA, LPS}

HDL and LDL were measured at Associated Medical Sciences Clinical Service Center, Chiang Mai University. Immunoglobulin A ( $\operatorname{Ig} \mathrm{A})$ level was determined using Elabscience Human IgA ELISA Kit and the amount of lipopolysaccharide (LPS) was determined using MyBioSource human lipopolysaccharides ELISA Kit as per the manufacturer's instructions.

\section{Statistical analysis}

Data were analyzed using STATA15. Paired-sample $\mathrm{t}$-test was used to detect within-group differences in lipid concentrations, IgA and LPS.

\section{RESULTS}

Ten hypercholesterolemic subjects ( 3 male and 7 female) were selected for the study. The average age of the subjects was $43.40 \pm 16.37$ years at the time of enrolment for the study. The subjects are non-diabetic and non-smokers but $20 \%$ of the subjects have the habit of drinking alcoholic beverages (Table 1).

\begin{tabular}{|c|c|}
\hline Characteristic & Probiotics ( $n=10)$ Number(Percentage) \\
\hline \multicolumn{2}{|l|}{ Gender } \\
\hline Male & $3(30.0)$ \\
\hline Female & $7(70.0)$ \\
\hline \multicolumn{2}{|l|}{ Age } \\
\hline$\leq 30$ & $3(30.0)$ \\
\hline $31-59$ & $6(60.0)$ \\
\hline 60 or more & $1(10.0)$ \\
\hline Mean $\pm S D$ & $43.40 \pm 16.37$ \\
\hline \multicolumn{2}{|l|}{ Diabetes } \\
\hline Yes & 0 \\
\hline No & $10(100.0)$ \\
\hline \multicolumn{2}{|l|}{ Smoking } \\
\hline Yes & 0 \\
\hline No & $10(100.0)$ \\
\hline \multicolumn{2}{|l|}{ Alcohol drinking } \\
\hline Yes & $2(20.0)$ \\
\hline No & $8(80.0)$ \\
\hline
\end{tabular}

Asian Journal of Medical Sciences | Jan-Feb 2020 | Vol 11 | Issue 1 


\section{Change in HDL-C and LDL-C level}

The LDL and HDL levels were recorded at baseline and after 4 weeks of L. paracasei HII01 supplementation. The level of LDL and HDL at baseline (Pre-treatment) was $156.80 \pm 35.94$ and $56.90 \pm 10.65 \mathrm{mg} / \mathrm{DL}$, respectively. Whereas after 4 weeks of probiotic intervention, level of LDL and HDL were changed to $139.40 \pm 36.41$ and $62.90 \pm 9.90 \mathrm{mg} / \mathrm{DL}$, respectively ( $p<0.01$ ) (Figure 1 and 2). After the probiotic intervention, a significant increase in HDL and a decrease in LDL levels were observed.

\section{Change in IgA and LPS content}

The concentrations of $\operatorname{IgA}$ and LPS were altered in hypercholesterolemic subjects after the probiotic supplementation. The average of $446.31 \pm 262$ and $939.62 \pm 758.52 \mathrm{ng} / \mathrm{ml}$ of $\mathrm{IgA}$ values was observed at baseline and after the probiotic intervention, respectively $(p=0.02$ ) (Figure 3 ). The baseline and after treatment of values of LPS was $113.53 \pm 40.07$ and $72.78 \pm 32.39 \mathrm{pg} / \mathrm{ml}$, respectively $(p<0.01$ ) (Figure 4).

\section{DISCUSSION}

The probiotic-based interventions are recently considered as a booster for the pharmacological agents to manage

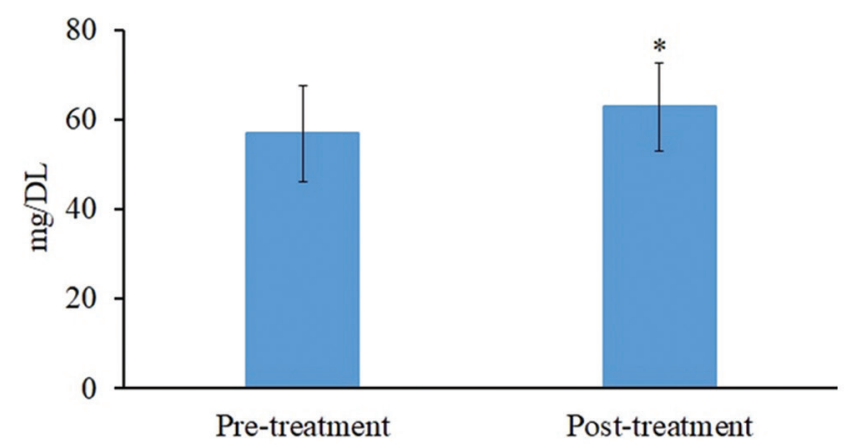

Figure 1: Changes in the level of HDL after 4 weeks of probiotic intervention in hypercholesterolemic patients. *indicates the significant difference between samples $(p<0.01)$.

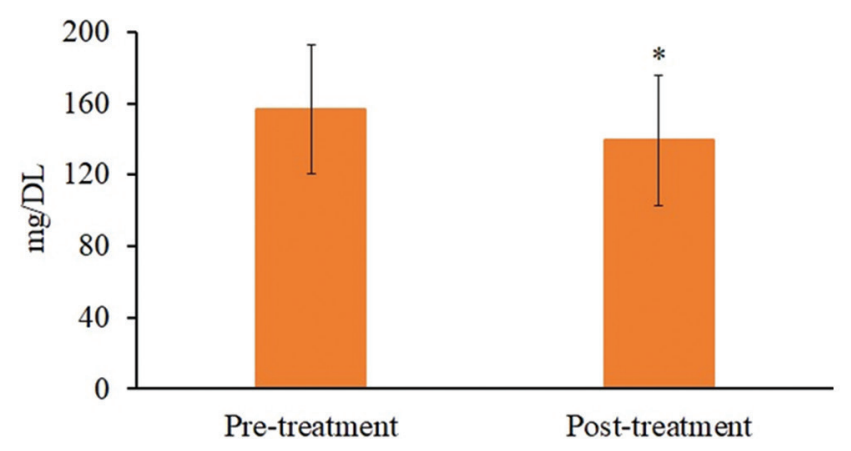

Figure 2: Changes in the level of LDL after 4 weeks of probiotic intervention in hypercholesterolemic patients. *indicates the significant difference between samples $(p<0.01)$. dyslipidemia. The changes in food habits that includesoy and other legumes, colored rice, red mold rice, vitamin-C, omega-3 fatty acids, and nicotinic acid in the regular diet can improve the lipid profile. ${ }^{21-26}$ Several clinical trials showed the beneficial effect of probiotic supplementation on the health status of hypercholesterolemic subjects.

Two-week supplementation of yogurt containing probiotic strains Bifidobacterium lactis and Lactobacillus acidophilus reduced the total cholesterol value while other lipid profiles were not affected significantly in healthy volunteers. ${ }^{27}$ The intervention of $L$. plantarum strain mixture, in the form of a capsule, for 12 weeks effectively reduced the total cholesterol, LDL-C, LDL-D/HDL-C ratio, and triglyceride levels in hypercholesterolemic subjects. ${ }^{28}$ Although, the meta-analysis of several randomized controlled clinical trials suggested that the supplementation of probiotic formulations decreased the triglycerides, LDL-C, and total cholesterol, and increased the HDL-C content when compared to the placebo control and baseline values. ${ }^{29,30}$

It is the truth that not all the probiotic interventions improved the lipid profile and other related parameters in human volunteers. The intervention of probiotic yogurt (made with L. acidophilus La5 and B. lactis Bb12) and

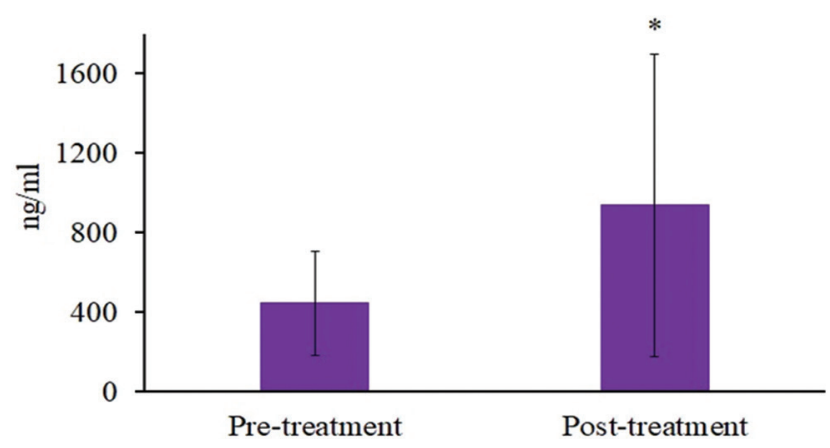

Figure 3: Changes in the level of IgA after 4 weeks of probiotic intervention in hypercholesterolemic patients. ${ }^{*}$ indicates the significant difference between samples $(p<0.02)$.

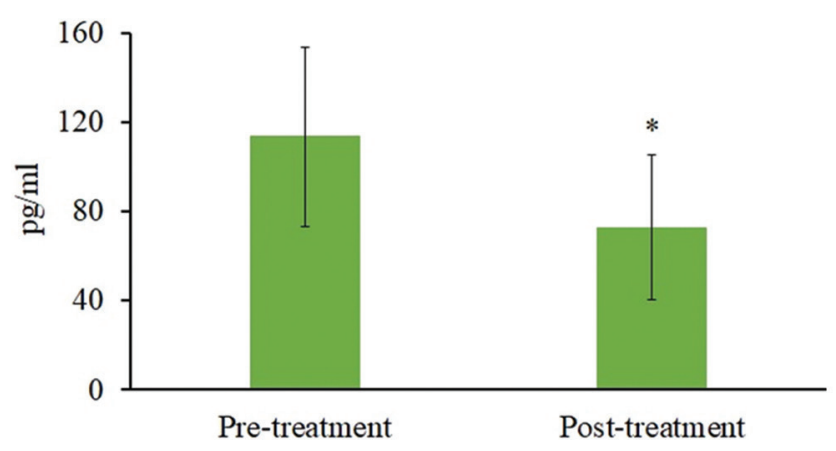

Figure 4: Changes in the level of LPS after 4 weeks of probiotic intervention in hypercholesterolemic patients. *indicates the significant difference between samples $(p<0.01)$. 
consumption of kefir were not improved the lipid profile of the subjects. ${ }^{31,32}$

Ecologic ${ }^{\circledR}$ Barrier (Mixture of B. bifidum W23, B. lactis W52, $L$ acidophilus W37, $L$ brevis W63, L casei W56, L salivarius W24, Lactococcus lactis W19 and L. lactis W58) supplementation significantly reduced the blood endotoxin level and improved the lipid profile in diabetic patients. ${ }^{33}$ Likely, the supplementation of the probiotic mixture (L acidophilus T16, B. bifidum BIA-6, B. lactis BIA-6, and B. longum LAF-5) with or without prebiotics (maltodextrin) reduced the endotoxin level and improved inflammatory markers in hemodialysis patients. ${ }^{34}$

The results of the current study supported that the supplementation of lyophilized L. paracasei HII01 amended the lipid profile in hypercholesterolemic patients. Particularly, the consumption of HII01 significantly increased the HDL level $(p<0.01)$ (Figure 1) and decreased the LDL level $(p<0.01)$ (Figure 2).

The IgA level was significantly $(p<0.02)$ increased after intervention, but the standard deviation value was not significant (Figure 3). Thus, the result of this particular parameter could not be considered as an acceptable outcome of the probiotic intervention. Further experimental evidence is needed to support the immune modulatory activity of the L. paracasei HII01 strain in hypercholesterolemic subjects.

The LPS concentration was reduced drastically after the probiotic intervention, which indicates that the supplemented probiotics improved the hot gut-microbiota, and reduced the release of endotoxin in the bloodstream. The results suggested that the supplementation of $L$ paracasei HII01 could diminish the toxicity in the blood (Figure 4).

\section{CONCLUSION}

As per our knowledge, this is the primary study on the cholesterol-lowering property of L. paracasei. The results suggested that the consumption of $12.5 \times 10^{10}$ cells of L. paracasei HII01 per day for 12 weeks significantly improved the blood lipid profile, endotoxin and IgA levels in hypercholesterolemic patients. Nonetheless, the current study has some downsides include limited sample size, no-placebo control, and limited studied parameters. Thus, a further extended study is obligatory with additional parameters to confirm the results of the present study.

\section{ACKNOWLEDGEMENT}

The authors would like to acknowledge the financial support from Center of Excellence on Medical Biotechnology
(CEMB), The S\&T Postgraduate Education and Research Development Office (PERDO), The Commission on Higher Education (CHE), Thailand. Authors also gratefully acknowledge Chiang Mai University grant (CMU-grant) for the support.We would also like acknowledge Lactomason Co., Ltd., South Korea for the technical support.Authors also gratefully acknowledge Brain Science and Engineering Innovation Research Group, Mae Fah Luang University grant (2019) (MFU-grant no. 611U109005) and 2020, Thailand for the support.

\section{REFERENCES}

1. Yusuf S, Hawken S, Ounpuu S, Dans T, Avezum A, Lanas F, et al.; INTERHEART study investigators. Effect of potentially modifiable risk factors associated with $\mathrm{Ml}$ in 52 countries (the INTERHEART study): case-control study. Lancet 2004; 364:937-952.

2. Grundy SM, Cleeman JI, Merz CN, Brewer HB Jr, Clark LT, Hunninghake DB, et al. National Heart, Lung, and Blood Institute; American College of Cardiology Foundation; American Heart Association. Implications of recent clinical trials for the National Cholesterol Education Program Adult Treatment Panel III guidelines. Circulation 2004; 110: 227-239.

3. Gordon DJ, Probstfield JL, Garrison RJ, Neaton JD, Castelli WP, Knoke JD, et al. High-density lipoprotein cholesterol and cardiovascular disease. Four prospective American studies. Circulation 1989; 79:8-15.

4. Briel M, Ferreira-Gonzalez I, You JJ, Karanicolas PJ, Akl EA, Wu $\mathrm{P}$, et al. Association between change in high density lipoprotein cholesterol and cardiovascular disease morbidity and mortality: systematic review and meta-regression analysis. Br Med J 2009; 338:b92.

5. Baigent C, Keech A, Kearney PM, Blackwell L, Buck G, Pollicino C, et al.; Cholesterol Treatment Trialists' (CTT) Collaborators. Efficacy and safety of cholesterol-lowering treatment: prospective meta-analysis of data from 90,056 participants in 14 randomised trials of statins. Lancet 2005; 366:1267-1278.

6. LaRosa JC, Grundy SM, Waters DD, Shear C, Barter P, Fruchart JC, et al. Treating to New Targets (TNT) Investigators. Intensive lipid lowering with atorvastatin in patients with stable coronary disease. N Engl J Med 2005; 352:1425-1435.

7. Cannon CP, Braunwald E, McCabe CH, Rader DJ, Rouleau JL, Belder R, et al.; Pravastatin or Atorvastatin Evaluation and Infection Therapy-Thrombolysis in Myocardial Infarction 22 Investigators. Intensive versus moderate lipid lowering with statins after acute coronary syndromes. N Engl J Med 2004; 350:1495-1504.

8. Miller M. Dyslipidemia and cardiovascular risk: the importance of early prevention. Q J Med 2009; 102:657-667.

9. Sivamaruthi BS, Kesika P, Prasanth MI and Chaiyasut C. A mini review on antidiabetic properties of fermented foods. Nutrients 2018; 10: 1973.

10. Sivamaruthi BS, Kesika $P$, Suganthy $N$ and Chaiyasut C. A review on role of microbiome in obesity and antiobesity properties of probiotic supplements. Biomed Res Int 2019; 2019: 3291367.

11. Blaabjerg S,Artzi DM and Aabenhus R. Probiotics for the prevention of antibiotic-associated diarrhea in outpatients-a systematic review and meta-analysis. Antibiotics (Basel) 2017; 6: 21.

12. Sivamaruthi BS. A comprehensive review on clinical outcome of probiotic and synbiotic therapy for inflammatory bowel diseases. 
Asian Pac J Trop Biomed 2018; 8: 179-186.

13. Sivamaruthi BS, Kesika $P$ and Chaiyasut C. Probiotic based therapy for atopic dermatitis: Outcomes of clinical studies. Asian Pac J Trop Biomed 2018; 8: 328-332.

14. Sivamaruthi BS, Kesika $P$ and Chaiyasut $C$. Influence of probiotic supplementation on climacteric symptoms in menopausal women-A mini review. Int J App Pharm 2018; 10: 43-46.

15. Sivamaruthi BS, Prasanth $\mathrm{MI}$, Kesika $P$ and Chaiyasut $C$. Probiotics in human mental health and diseases-A mini review. Trop J Pharm Res 2019; 18: 889-895.

16. Sivamaruthi BS, Kesika $P$ and Chaiyasut C. A review on antiaging properties of probiotics. Int J App Pharm 2018; 10; 23-27.

17. Peterbauer $C$, Maischberger $T$ and Haltrich D. Food-grade gene expression in lactic acid bacteria. Biotechnol J 2011; 6:1147-1161.

18. Ooi $L$ and Liong MT. Cholesterol-lowering effects of probiotics and prebiotics: A review of in vivo and in vitro findings. Int $\mathrm{J} \mathrm{Mol}$ Sci 2010; 11: 2499-2522.

19. Nguyen TDT, Kang JH and Lee MS. Characterization of Lactobacillus plantarum $\mathrm{PH} 04$, a potential probiotic bacterium with cholesterol-lowering effects. Int J Food Microbiol 2007; 113: 358-361.

20. Jeun J, Kim S, Cho SY, Jun HJ, Park HJ, Seo JG, et al. Hypocholesterolemic effects of Lactobacillus plantarum KCTC3928 by increased bile acid excretion in C57BL/6 mice. Nutrition 2010; 26(3):321-30.

21. Hu FB, Bronner L, Willett WC, Stampfer MJ, Rexrode KM, Albert CM, et al. Fish and omega 3 fatty acid intake and risk of coronary heart disease in women. JAMA 2002; 287: 1815-1821.

22. Anderson JW, Johnstone BM and Cooke Newell ME. Metaanalysis of the effects of soyprotein on serumlipids. N Engl $\mathrm{J}$ Med 1995; 333: 276-282.

23. McRae MP. Vitamin C supplementation lowers serum low density lipoprotein cholesterol and triglycerides: a meta-analysis of 13 randomized controlled trials. J Chiropr Med 2008; 7:48-58.

24. Bazzano LA, Thompson AM, Tees MT, Nguyen $\mathrm{CH}$ and Winham DM. Non-soy legume consumption lowers cholesterol levels: a meta-analysis of randomized controlled trials. Nutr Metab Cardiovasc Dis 2011; 21:94-103.

25. Carlson LA and Rosenhamer G. Reduction of mortality in the
Stockholm ischaemic heart disease secondary prevention study by combined treatment with clofibrate and nicotinic acid. Acta Med Scand 1988; 223:405-418.

26. Lin CC, Li TC and Lai MM. Went rice in subjects with hyperlipidemia. Eur J Endocrinol 2005; 153:679-686.

27. Ataie-Jafari A, Larijani B, Alavi Majd H and Tahbaz F. Cholesterollowering effect of probiotic yogurt in comparison with ordinary yogurt in mildly to moderately hypercholesterolemic subjects. Ann Nutr Metab 2009; 54(1):22-27.

28. Fuentes MC, Lajo T, Carrion JM and Cune J. A randomized clinical trial evaluating a proprietary mixture of Lactobacillus plantarum strains for lowering cholesterol. Med J Nutrition Metab 2016; 9: 125-135.

29. Agerholm-Larsen L, Bell ML, Grunwald GK and Astrup A. The effect of a probiotic milk product on plasma cholesterol: a metaanalysis of short-term intervention studies. Eur J Clin Nutr 2000; 54(11): 856-860.

30. Guo Z, Liu XM, Zhang QX, Shen Z, Tian FW, Zhang H, et al. Influence of consumption of probiotics on the plasma lipid profile: a meta-analysis of randomised controlled trials. Nutr Metab Cardiovasc Dis 2011; 21(11):844-850.

31. Ivey KL, Hodgson JM, Kerr DA, Thompson PL, Stojceski B and Prince RL. The effect of yoghurt and its probiotics on blood pressure and serum lipid profile; a randomised controlled trial. Nutr Metab Cardiovasc Dis 2015; 25(1):46-51.

32. St-onge MP, Farnworth ER, Savard T, Chabot D, Mafu A and Jones PJ. Kefir consumption does not alter plasma lipid levels or cholesterol fractional synthesis rates relative to milk in hyperlipidemic men: a randomized controlled trial [ISRCTN10820810]. BMC Complement Altern Med 2002; 2:1-7.

33. Sabico S, Al-Mashharawi A, Al-Daghri NM, Wani K, Amer OE, Hussain DS, et al. Effects of a 6-month multi-strain probiotics supplementation in endotoxemic, inflammatory and cardiometabolic status of T2DM patients: A randomized, doubleblind, placebo-controlled trial. Clin Nutr 2019; 38(4):1561-1569.

34. Haghighat $N$, Mohammadshahi $M$, Shayanpour $S$ and Haghighizadeh $\mathrm{MH}$. Effects of synbiotics and probiotics supplementation on serum levels of endotoxin, heat shock protein 70 antibodies and inflammatory markers in hemodialysis patients: A randomized double-blinded controlled trial. Probiotics Antimicrob Proteins 2019; doi: 10.1007/s12602-018-9509-5.

\footnotetext{
Authors Contribution:

CC- Concept and design of the study, manuscript preparation, critical revision of the manuscript; BSS- Statistically analyzed and interpreted, manuscript preparation, critical revision of the manuscript; SS- Concept and design of the study, statistically analyzed and interpreted; YT- Concept and design of the study, statistically analyzed and interpreted; PS- Manuscript preparation, critical revision of the manuscript

Work attributed to:

Innovation Center for Holistic Health, Nutraceuticals and Cosmeceuticals, Faculty of Pharmacy, Chiang Mai University, Thailand;

Brain Science and Engineering Innovation Research Group, School of Anti-Aging and Regenerative Medicine, Mae Fah Luang University, Thailand.

Orcid ID:

Dr. Chaiyavat Chaiyasut- https://orcid.org/0000-0002-1633-2419

Dr. Bhagavathi Sundaram Sivamaruthi-10 https://orcid.org/0000-0002-5499-8350

Dr. Sasithorn Sirilun- https://orcid.org/0000-0002-1508-2358

Ms. Yaowalak Tirawat-1 https://orcid.org/0000-0002-4034-9325

Dr. Phakkharawat Sittiprapaporn-10 https://orcid.org/0000-0002-4103-9396

Source of Support: Center of Excellence on Medical Biotechnology (CEMB), The S\&T Postgraduate Education and Research Development Office (PERDO), The Commission on Higher Education (CHE), Thailand; Chiang Mai University grant (CMU-grant); Brain Science and Engineering Innovation Research Group, Mae Fah Luang University grant (2019) (MFU-grant no. 611U109005) and 2020, Thailand, Conflict of Interest: None.
} 